\title{
SOLUBILIDADE E REATIVIDADE DE GASES
}

\author{
Luciana Almeida Silva, Luiz Souza Carvalho, Wilson Araújo Lopes, Pedro Afonso de Paula Pereira e Jailson B. de Andrade* \\ Instituto de Química, Universidade Federal da Bahia, 40170-115 Salvador - BA, Brasil \\ Instituto Nacional de Ciência e Tecnologia de Energia e Ambiente, Universidade Federal da Bahia, 40170-290 Salvador - BA, Brasil
}

Recebido em 17/10/2016; aceito em 17/01/2017; publicado na web em 24/03/2017

\begin{abstract}
REACTIVITY AND SOLUBILITY OF GASES. This paper deals with the solubility and reactivity of gases, especially in water, covering the main aspects that influence the dissolution process, namely polarizability of atoms or molecules in gas phase and their ability to react with the solvent. The discussion highlights the importance of solubility of gases in several biological processes, such as respiration and photosynthesis, hydrogen storage and industrial processes, as the production of carbonated beverages. The discussion also addresses the importance of gas solubility in atmospheric chemistry and aquatic environments.
\end{abstract}

Keywords: solubility of gases; biological processes, respiration; photosynthesis; carbonated beverages; hydrogen storage.

\section{INTRODUÇÃO}

Há cerca de dois bilhões de anos alguns organismos passaram a realizar fotossíntese, o que desencadeou uma grande evolução dos seres vivos. A crescente concentração de gases oxidantes como oxigênio e ozônio na baixa troposfera obrigou os organismos a se refugiarem na água. ${ }^{1,2}$ Com o aumento progressivo da pressão parcial na atmosfera, o oxigênio foi lentamente sendo dissolvido na água e desta forma os organismos foram aos poucos se adaptando ao novo ambiente, até que nos últimos 500 milhões de anos saíram da água para povoar a superfície da Terra envolta por uma tênue camada de gases. Os gases que compõem a atmosfera mantêm as condições ideais na superfície do planeta para a criação e manutenção da vida como, por exemplo, o oxigênio, vital para os seres aeróbios, o dióxido de carbono, usado na fotossíntese e o nitrogênio, convertido pelas bactérias fixadoras de nitrogênio e utilizado pelas plantas, sendo essencial na construção de biomoléculas; além de atuar como um escudo protetor contra radiação cósmica de alta energia..$^{1,3}$ Muitos desses processos ocorrem em meio aquoso e são dependentes da capacidade de dissolução desses gases em água.

Os gases são definidos como um conjunto de moléculas ou átomos, muito separados entre si, em movimento permanente e aleatório, com trajetórias pouco influenciadas por forças interatômicas ou intermoleculares. O comportamento de cada gás pode ser descrito por uma equação que estabelece a relação entre as quatro variáveis que definem seu estado, volume $(V)$, quantidade de matéria $(n)$, temperatura $(T)$ e pressão $(p), p=f(T, V, n) .{ }^{4}$ Nas condições de temperatura e pressão ordinárias $\left(25^{\circ} \mathrm{C}\right.$ e $\left.1 \mathrm{~atm}\right)$, o estado gasoso predomina quando as forças interatômicas ou intermoleculares inexistem (gases perfeitos) ou são de baixa intensidade, a exemplo das forças de dispersão de London, que são interações resultantes de formação de dipolos instantâneos, típicas entre moléculas apolares. No entanto, vale ressaltar que o estado gasoso não é exclusivo de moléculas apolares (Quadro 1). Há diversos tipos de gases constituídos por moléculas polares, nas condições ordinárias de temperatura e pressão, como são os casos do dióxido de enxofre, dos haletos de hidrogênio e da amônia, cujas interações do tipo dipolo-dipolo, ou até mesmo ligações hidrogênio, não são suficientemente intensas para levá-los à forma condensada.

As interações intermoleculares fracas também irão limitar a

*e-mail: jailsondeandrade@gmail.com solubilidade de gases em fases de dispersão líquidas ou sólidas. Por outro lado, quando a fase de dispersão é um gás, a formação da mistura independe de interações intermoleculares e os gases serão miscíveis em qualquer proporção.

\section{SOLUBILIDADE DE GASES}

\section{Solubilidade em água}

Quando a fase de dispersão, ou solvente, é um líquido, a solubilidade do gás é governada pela lei de Henry, proposta em 1801 pelo químico inglês William Henry, a qual pode ser escrita como na equação 1

$$
s_{\mathrm{G}}=k_{\mathrm{H}} p_{\mathrm{G}}
$$

em que $s_{\mathrm{G}}$ é a solubilidade do gás, $k_{\mathrm{H}}$ a constante de Henry e $p_{\mathrm{G}}$ a pressão parcial do gás.

A constante de Henry, $k_{\mathrm{H}}$, depende da natureza do gás, do solvente e da temperatura. A Tabela 1 lista os valores de $k_{\mathrm{H}}$ de alguns gases.

Os valores de $k_{\mathrm{H}}$ mostrados na Tabela 1 são referentes a soluções formadas por gases constituídos de átomos isolados, caso dos gases nobres, ou por moléculas apolares dispersos em um solvente polar, a água, a uma dada temperatura. Fixando-se dois parâmetros, como temperatura e tipo de solvente, é possível perceber que a magnitude do valor de $k_{\mathrm{H}}$ é dependente da intensidade das forças que atuam entre átomos ou moléculas do gás e moléculas do líquido, sendo que predominam as interações do tipo dipolo permanente-dipolo induzido. A intensidade destas interações dependerá da polarizabilidade das moléculas ou átomos que compõem o gás. A polarizabilidade de uma espécie química é uma grandeza física que indica a facilidade com que a sua densidade eletrônica pode ser distorcida, formando uma distribuição assimétrica, os dipolos instantâneos ou induzidos. ${ }^{9-11}$ No caso dos gases nobres, por exemplo, a solubilidade em água é muito baixa, tornando-se maior à medida que aumenta a população de elétrons no átomo, o que permite maior polarizabilidade (Tabela 2).

A baixa solubilidade do gás hélio em água é usada, por exemplo, para reduzir riscos em mergulhos profundos. Os cilindros de ar comprimido que usam nitrogênio para fazer o balanço de oxigênio não são adequados para este fim. A molécula de nitrogênio possui nuvem eletrônica compacta, pouco suscetível à polarização, visto que grande parte dos elétrons de valência está comprometida com a ligação 
Quadro 1. Estruturas moleculares e momento de dipolo $(\mu)$ de alguns compostos gasosos. ${ }^{5-8}$

\begin{tabular}{|c|c|c|c|}
\hline $\begin{array}{c}\mathbf{N} \equiv \mathbf{N} \\
\mu=0\end{array}$ & $\begin{array}{c}\mathbf{O}=\mathbf{O} \\
\mu=0\end{array}$ & $\underset{\mu=0}{\mathbf{O}=\mathbf{C}=\mathbf{O}}$ & $\underset{\mu=0,316 \mathrm{D}}{\mathbf{O}^{-}}$ \\
\hline $\begin{array}{l}\mathbf{N}=\mathbf{O} \\
\mu=0,159 \mathrm{D}\end{array}$ & $\begin{array}{c}\mathbf{N}=\mathbf{N}=\mathbf{O} \\
\mu=0,166 \mathrm{D}\end{array}$ & $\mu=0$ & \\
\hline$\underset{\mu=1,47 \mathrm{D}}{\mathbf{H}_{\mathbf{H}}^{-}}$ & $\begin{array}{l}\mathbf{H}-\mathbf{F} \\
\mu=1,82 \mathrm{D}\end{array}$ & $\begin{array}{l}\mathbf{H}-\mathbf{C l} \\
\mu=1,10 \mathrm{D}\end{array}$ & $\begin{array}{c}\mathbf{C l}-\mathbf{C l} \\
\mu=0\end{array}$ \\
\hline${ }_{\mathbf{H}}={ }^{\mathrm{C}}$ & $\underset{\mu=0}{H}=\left.\right|_{C_{C}^{H}} ^{H}$ & $\prod_{\mu=0,084 \mathrm{D}} \mathbf{H}$ & $\prod_{\mu=0}^{\mathbf{H}}$ \\
\hline
\end{tabular}

Tabela 1. Constates de Henry para alguns gases constituídos de átomos ou moléculas apolares. Valores válidos para solubilidade em água a $20{ }^{\circ} \mathrm{C}^{9}$

\begin{tabular}{cc}
\hline Gás & $k_{\mathrm{H}}\left(\mathrm{mol} \mathrm{L}^{-1} \mathrm{~atm}^{-1}\right)$ \\
\hline $\mathrm{He}$ & $3,7 \times 10^{-4}$ \\
$\mathrm{Ne}$ & $5,0 \times 10^{-4}$ \\
$\mathrm{~N}_{2}$ & $7,0 \times 10^{-4}$ \\
$\mathrm{H}_{2}$ & $8,5 \times 10^{-4}$ \\
$\mathrm{O}_{2}$ & $1,3 \times 10^{-3}$ \\
$\mathrm{Ar}$ & $1,5 \times 10^{-3}$ \\
$\mathrm{CO}_{2}$ & $2,3 \times 10^{-2}$ \\
\hline
\end{tabular}

Tabela 2. Solubilidade em fração molar $(X)$ de gases nobres em água a $20^{\circ} \mathrm{C}$ e pressão normal ${ }^{8}$

\begin{tabular}{cc}
\hline Gás Nobre & Solubilidade em fração molar \\
\hline $\mathrm{He}$ & $7,044 \times 10^{-6}$ \\
$\mathrm{Ne}$ & $8,395 \times 10^{-6}$ \\
$\mathrm{Ar}$ & $2,748 \times 10^{-5}$ \\
$\mathrm{Kr}$ & $5,041 \times 10^{-5}$ \\
$\mathrm{Xe}$ & $9,051 \times 10^{-5}$ \\
$\mathrm{Rn}$ & $1,945 \times 10^{-4}$ \\
\hline
\end{tabular}

entre os dois átomos (Quadro 1). Como consequência, as interações dipolo permanente-dipolo induzido são de baixa intensidade e o gás nitrogênio terá baixa solubilidade em água $(2,33 \mathrm{~mL} / 100 \mathrm{~g}$ de água a $0{ }^{\circ} \mathrm{C}$ e $1,42 \mathrm{~mL} / 100 \mathrm{~g}$ de água a $\left.40{ }^{\circ} \mathrm{C}\right) .{ }^{8,13} \mathrm{~A}$ baixa solubilidade do nitrogênio em água implica também em baixa solubilidade no sangue. Entretanto, esta aumenta à medida que aumenta a pressão, como previsto pela lei de Henry. Em grandes profundidades, por conta da elevada pressão, o nitrogênio torna-se perigosamente mais solúvel no sangue, solubilidade esta que se reduz drasticamente ao subir para a superfície. Na descompressão, a degasagem provoca a formação de inúmeras bolhas no sangue, em um processo conhecido como embolia, que pode bloquear ou romper vasos capilares muito finos, impedindo que o oxigênio chegue aos tecidos, o que pode ser fatal! Quando o hélio é usado no balanço de oxigênio em cilindros para mergulho, o risco é reduzido visto que sua solubilidade no plasma é menor e o tamanho reduzido do átomo de hélio permite que atravesse a membrana celular sem causar danos. A mistura contendo hélio também evita o fenômeno conhecido como narcose por nitrogênio, que consiste no desenvolvimento de euforia, falsa sensação de segurança e aparente estado de embriaguez em mergulhos que atingem pressões superiores a 4 atmosferas quando ar comprimido é usado. Apesar de quimicamente inerte, o nitrogênio submetido a elevadas pressões torna-se lipossolúvel e interfere na transmissão de impulsos nervosos. ${ }^{14,15}$

Hidrocarbonetos alifáticos, os alcanos de $\mathrm{C} 1$ a C4 são gases no estado padrão e também apresentam baixa solubilidade em água. As interações nesse caso também serão do tipo dipolo permanente-dipolo induzido, visto que tratam-se de moléculas apolares ou com momento de dipolo muito baixo (Quadro 1). O metano é o menor dos hidrocarbonetos, apresentando nuvem eletrônica compacta, pouco suscetível à polarização, resultando na menor solubilidade em água dentro desta série. O etano, com dois átomos de carbono é mais polarizável que o metano, o que facilita as interações dipolo permanente-dipolo induzido com a água, tornando-o mais solúvel. Porém, à medida que aumenta a cadeia, o hidrocarboneto torna-se mais hidrofóbico, visto que o dipolo induzido pela água será menos intenso em função da menor polarizabilidade da molécula; como consequência, há uma redução de solubilidade do etano ao butano (Figura 1).

\section{Solubilidade e reações químicas}

\section{Moléculas Apolares}

$\mathrm{CO}_{2}$ é uma molécula linear apolar, com densidade eletrônica que permite polarização (Quadro 1). Aliado a isso, dióxido de carbono atua como um ácido fraco de Lewis que reage com água para produzir 


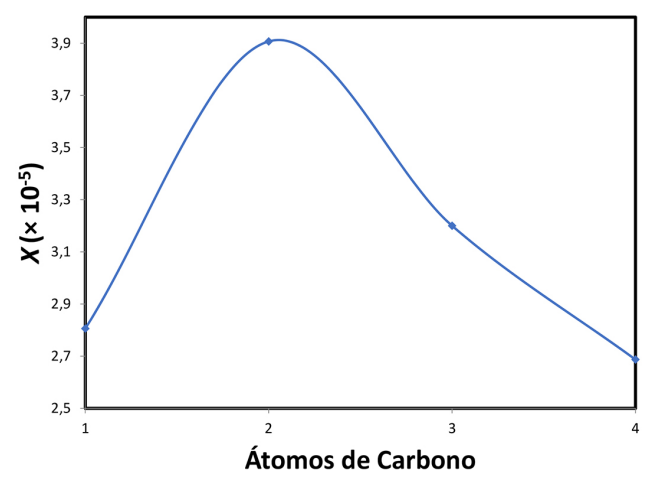

Figura 1. Solubilidade em fração molar $(X)$ de alcanos alifáticos de cadeia curta (C1 a C4) em água a $20^{\circ} \mathrm{C}$. Dados de solubilidade extraídos da ref. 8

diferentes espécies em solução (equações 2-4). Essas características lhe garantem elevada solubilidade em água $\left(90,1 \mathrm{~mL} / 100 \mathrm{~g}\right.$ de $\mathrm{H}_{2} \mathrm{O}$ a $\left.20{ }^{\circ} \mathrm{C}\right) .{ }^{8}$ A espécie predominante em solução irá depender do $\mathrm{pH}$ do meio e das respectivas constantes de equilíbrio.

$$
\begin{gathered}
\mathrm{CO}_{2}(\mathrm{~g}) \rightleftarrows \mathrm{CO}_{2}(\mathrm{aq}) \\
k_{\mathrm{H}}=2,3 \times 10^{-2} \mathrm{~mol} \mathrm{~L}^{-1} \mathrm{~atm}^{-1} \\
\mathrm{CO}_{2}(\mathrm{aq})+\mathrm{H}_{2} \mathrm{O}(\mathrm{l}) \rightleftarrows \mathrm{H}_{3} \mathrm{O}^{+}(\mathrm{aq})+\mathrm{HCO}_{3}^{-}(\mathrm{aq}) \\
\mathrm{Ka}_{1}=4,3 \times 10^{-7} \mathrm{~mol} \mathrm{~L}{ }^{-1} \\
\mathrm{HCO}_{3}-(\mathrm{aq})+\mathrm{H}_{2} \mathrm{O}(\mathrm{l}) \rightleftarrows \mathrm{H}_{3} \mathrm{O}^{+}(\mathrm{aq})+\mathrm{CO}_{3}{ }^{2-}(\mathrm{aq}) \\
\mathrm{Ka}_{2}=4,7 \times 10^{-11} \mathrm{~mol} \mathrm{~L}^{-1}
\end{gathered}
$$

Assim como o $\mathrm{CO}_{2}$, muitos gases têm a solubilidade aumentada em água em função de intensas interações intermoleculares que resultam em reações químicas. Por exemplo, os halogênios que se encontram na forma de gás no estado padrão, casos do $\mathrm{F}_{2}$ e $\mathrm{Cl}_{2}$, são constituídos de moléculas apolares, mas apresentam elevada solubilidade em água como consequência do elevado poder oxidante, especialmente do flúor $\left(\mathrm{E}^{\circ}=2,87 \mathrm{~V}\right)$. Em solução aquosa, flúor é totalmente reduzido a fluoreto ao oxidar a água (equação 5), enquanto que o cloro sofre desproporcionamento, resultando em cloreto e hipoclorito (equação 6). A solubilidade do cloro é de $247 \mathrm{~mL} / 100 \mathrm{~g}$ de água a $20{ }^{\circ} \mathrm{C},{ }^{13}$ porém, no equilíbrio estão presentes $\mathrm{Cl}_{2}$ hidratado e $\mathrm{HClO}$, espécies denominadas de cloro ativo, além do cloreto. $\mathrm{O}$ cloro ativo é definido como a quantidade de cloro em solução capaz de liberar $\mathrm{Cl}_{2}$ quando em meio ácido. ${ }^{16}$ Para manter o elevado teor de cloro ativo em águas sanitárias, por exemplo, as soluções são preparadas em meio básico, com valores de $\mathrm{pH}$ que podem variar entre 11,5-13,5.

$$
\begin{gathered}
\mathrm{F}_{2}(\mathrm{~g})+\mathrm{H}_{2} \mathrm{O}(\mathrm{l}) \rightarrow 2 \mathrm{HF}(\mathrm{aq})+1 / 2 \mathrm{O}_{2}(\mathrm{~g}) \\
\mathrm{Cl}_{2}(\mathrm{~g})+\mathrm{H}_{2} \mathrm{O}(\mathrm{l}) \rightleftarrows \mathrm{H}^{+}(\mathrm{aq})+\mathrm{Cl}^{-}(\mathrm{aq})+\mathrm{HClO}(\mathrm{aq})
\end{gathered}
$$

\section{Moléculas Polares}

Os haletos de hidrogênio ( $\mathrm{HF}, \mathrm{HCl}, \mathrm{HBr}$ e $\mathrm{HI}$ ) são polares e interagem via forças intermoleculares do tipo dipolo-dipolo mas, mesmo assim, encontram-se na forma gasosa no estado padrão, à temperatura ambiente, inclusive o HF, que interage via ligações hidrogênio (p.e. $19,9^{\circ} \mathrm{C}$ ). Esses ácidos se dissociam quase que completamente em água, à exceção do HF, formando misturas azeotrópicas em todos os casos. As interações predominantes nas soluções aquosas serão do tipo íon-dipolo, em razão da dissociação dos ácidos. Apesar do HF se dissociar apenas parcialmente, consequência da alta energia de dissociação e da estrutura polimérica, a elevada solubilidade é garantida pelas fortes ligações hidrogênio com a água. O HF é comercializado em solução aquosa com concentrações que variam de $47-51 \%$.
Os óxidos de enxofre, $\mathrm{SO}_{2}$ e $\mathrm{SO}_{3}$, em fase gasosa são considerados importantes poluentes atmosféricos. $\mathrm{O} \mathrm{SO}_{2}$ tem estrutura angular e, portanto, polar, com momento de dipolo igual a 1,63 D, enquanto que o $\mathrm{SO}_{3}$ gasoso ocorre com estrutura trigonal plana, com momento de dipolo nulo, ou seja, a molécula é apolar (Quadro 1). Apesar das diferenças estruturais, ambos interagem fortemente com a água, resultando em alta solubilidade acompanhada de reações químicas. As duas moléculas atuarão como receptoras de elétrons, sendo, então, ácidos de Lewis. Os átomos de oxigênio ligados ao enxofre deslocam densidade eletrônica, o que contribui para aumentar sua eletrodeficiência. Desta forma, o trióxido de enxofre, com maior número de átomos de oxigênio, é um ácido mais forte que o dióxido de enxofre e reage imediatamente com água para formar ácido sulfúrico (equação 7).

$$
\mathrm{SO}_{3}(\mathrm{~g})+\mathrm{H}_{2} \mathrm{O}(\mathrm{l}) \rightarrow \mathrm{H}_{2} \mathrm{SO}_{4}(\mathrm{l})
$$

A polaridade e acidez moderada do dióxido de enxofre permitem boa solubilidade em água $(22,8 \mathrm{~g} / 100 \mathrm{~g}$ de água $),{ }^{8}$ visto que a dissolução é acompanhada de reações químicas, cujas espécies predominantes em solução irão depender do pH do meio (equações 8-10):

$$
\begin{gathered}
\mathrm{SO}_{2}(\mathrm{~g})+\mathrm{H}_{2} \mathrm{O}(\mathrm{l}) \rightleftarrows \mathrm{SO}_{2} \cdot \mathrm{H}_{2} \mathrm{O}(\mathrm{aq}) \\
k_{\mathrm{H}}=1,23 \mathrm{~mol} \mathrm{~L}^{-1} \mathrm{~atm}^{-1} \\
\mathrm{SO}_{2} \cdot \mathrm{H}_{2} \mathrm{O}(\mathrm{aq})+\mathrm{H}_{2} \mathrm{O}(\mathrm{l}) \rightleftarrows \mathrm{HSO}_{3}^{-}(\mathrm{aq})+\mathrm{H}_{3} \mathrm{O}^{+}(\mathrm{aq}) \\
K=1,32 \times 10^{-2} \mathrm{~mol} \mathrm{~L}^{-1} \\
\mathrm{HSO}_{3}^{-}(\mathrm{aq})+\mathrm{H}_{2} \mathrm{O}(\mathrm{l}) \rightleftarrows \mathrm{SO}_{3}^{2-}(\mathrm{aq})+\mathrm{H}_{3} \mathrm{O}^{+}(\mathrm{aq}) \\
K=6,42 \times 10^{-8} \mathrm{~mol} \mathrm{~L}^{-1}
\end{gathered}
$$

As transformações de espécies oxigenadas de enxofre que ocorrem na troposfera envolvem os equilíbrios descritos pelas equações 8-10. Uma vez formado ou emitido para a atmosfera, $\mathrm{SO}_{2}$ é oxidado, tanto na fase gasosa quanto na fase aquosa (chuva, neblina, nevoeiro), produzindo ácido sulfúrico $\left(\mathrm{H}_{2} \mathrm{SO}_{4}\right)$ ou partículas neutralizadas sob forma de sulfato (Figura 2).

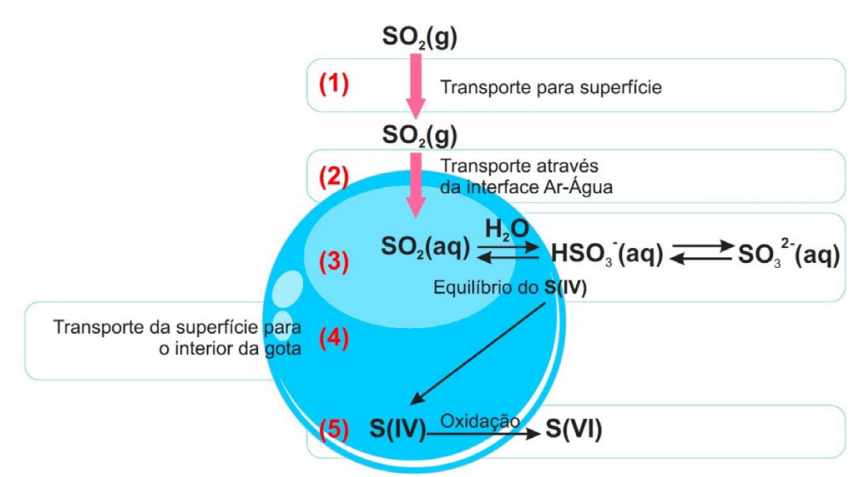

Figura 2. Conversão gás-partícula: esquema representativo da transferência de $\mathrm{SO}_{2}(g)$ para a fase aquosa ${ }^{3}$

O transporte de gases através da interface ar/água em gotículas permite que reações na atmosfera ocorram em meio aquoso, formando produtos com baixas pressões de vapor, tais como os ânions nitrato, sulfato e de ácidos carboxílicos. Alguns produtos de reações atmosféricas, a exemplo do ácido sulfúrico e compostos orgânicos altamente oxigenados, são resultado da troca de matéria entre as fases gasosa e particulada. Essa troca inclui a nucleação e crescimento de partículas finas, a adsorção de gases na superfície das partículas sólidas, a captação de água pelas partículas para formar soluções aquosas e a dissolução de traços de solutos gasosos nas gotículas. ${ }^{17}$ Esses 
processos são responsáveis, por exemplo, por parte do transporte e remoção de $\mathrm{SO}_{2}$ da fase gasosa na atmosfera, até a transformação final em sulfato na fase aquosa. $\mathrm{Na}$ faixa de $\mathrm{pH}$ correspondente à água na atmosfera ( $\mathrm{pH} 2 \mathrm{a} 6$ ), a maior parte do $\mathrm{SO}_{2}$ dissolvido encontra-se na forma do íon bissulfito, $\mathrm{HSO}_{3}^{-}{ }^{3}$ A conversão das espécies de $\mathrm{S}$ (IV) a $\mathrm{S}(\mathrm{VI})$, catalisada por cátions metálicos em presença de agentes oxidantes, ocorre em solução aquosa resultante do fenômeno de conversão gás-partícula, caso contrário essa e outras reações não seriam possíveis na atmosfera.

Outra possibilidade de conversão gás-partícula é a reação direta entre gases resultando em finas partículas sólidas dispersas no ar. Um exemplo é a reação de neutralização de amônia com cloreto de hidrogênio em fase gasosa que resulta em finas partículas de cloreto de amônio dispersas no ar, formando uma névoa. Essa reação é usada em um experimento clássico que ilustra a velocidade de difusão de gases e sua dependência com a massa molar (Figura 3$).{ }^{18}$ A reação de formação de $\mathrm{NH}_{4} \mathrm{Cl}$ (anel branco) ocorre na parte do tubo mais próxima à extremidade onde $\mathrm{o} \mathrm{HCl}$ é introduzido, indicando que este se difunde mais lentamente por ter maior massa molar.

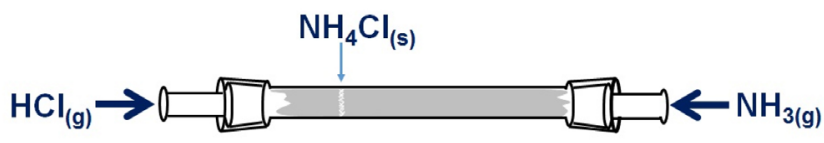

Figura 3. Experimento clássico que ilustra a lei de Graham

De acordo com Thomas Graham, a velocidade de difusão (v) de um gás é inversamente proporcional à raiz quadrada de sua massa molar $(M M)$ e a razão entre suas velocidades de difusão pode ser dada pela equação (11):

$$
\frac{v_{\mathrm{NH}_{3}}}{v_{\mathrm{HCl}}}=\sqrt{\frac{M M_{\mathrm{HCl}}}{M M_{N H_{3}}}}
$$

Processos químicos e biológicos denominados de desnitrificação geram compostos reduzidos de nitrogênio sob a forma de gás a partir do nitrato $\left(\mathrm{NO}_{3}^{-}\right)$, que são lançados na atmosfera (e.g. $\mathrm{NO}_{2}, \mathrm{NO}, \mathrm{N}_{2} \mathrm{O}$, $\mathrm{N}_{2}$; estruturas no Quadro 1). $\mathrm{O} \mathrm{N}_{2}$, tratado anteriormente, apresenta baixa solubilidade em água em função da baixa polarizabilidade da nuvem eletrônica. Óxido nitroso, $\mathrm{N}_{2} \mathrm{O}$, é pouco reativo e um poderoso gás de efeito estufa. Óxido nitroso e $\mathrm{CO}_{2}$ são isoeletrônicos, com estrutura linear, porém $\mathrm{N}_{2} \mathrm{O}$ é assimétrico, com um dos átomos de nitrogênio ocupando a posição central, o que resulta em um momento de dipolo de $0,166 \mathrm{D}$. A solubilidade de $\mathrm{N}_{2} \mathrm{O}$ em água $(65,6 \mathrm{~mL} / 100 \mathrm{~g}$ de $\mathrm{H}_{2} \mathrm{O}$ a $\left.20^{\circ} \mathrm{C}\right)^{13}$ é inferior a do $\mathrm{CO}_{2}\left(90,1 \mathrm{~mL} / 100 \mathrm{~g}\right.$ de $\mathrm{HO}$ a $\left.20^{\circ} \mathrm{C}\right),{ }^{8}$ que reage com água para formar bicarbonato. A baixa polaridade do óxido nitroso, no entanto, possibilita alta solubilidade em gorduras, tornando-o capaz de atravessar facilmente membranas celulares. Por ser lipossolúvel e apresentar efeito analgésico e sedativo, o óxido nitroso é usado na medicina e em procedimentos odontológicos para sedação consciente. A inalação do gás causa contrações involuntárias nos músculos da face, o que leva a pensar que o gás provoca risos, sendo assim chamado de gás hilariante. Já o dióxido de nitrogênio, $\mathrm{NO}_{2}$, apresenta estrutura angular, com momento de dipolo de $0,316 \mathrm{D}$, portanto, pouco polar. Dióxido de nitrogênio é um gás castanho muito reativo e desproporciona em água gerando ácido nítrico e óxido nítrico (equação 12). O óxido nítrico, NO, é um gás neutro e apresenta semelhança estrutural ao $\mathrm{N}_{2}$; porém, a molécula é assimétrica, resultando num pequeno momento de dipolo $(0,159 \mathrm{D})$ e maior polarizabilidade. Como consequência, o NO é ligeiramente mais solúvel que o $\mathrm{N}_{2}$ em água $\left(7,34 \mathrm{~mL} / 100 \mathrm{~g}\right.$ de $\mathrm{H}_{2} \mathrm{O}$ a $0{ }^{\circ} \mathrm{C}$ e $5,36 \mathrm{~mL} / 100 \mathrm{~g}$ de $\mathrm{H}_{2} \mathrm{O}$ a $\left.20{ }^{\circ} \mathrm{C}\right),{ }^{8,13}$ mas é menos solúvel que o $\mathrm{N}_{2} \mathrm{O}$ em função do menor momento de dipolo e menor polarizabilidade do primeiro. A ampla utilização de fertilizantes nitrogenados na agricultura tem contribuído para aumentar a quantidade dos óxidos de nitrogênio, $\mathrm{NO}$ e $\mathrm{NO}_{2}$, na atmosfera pelo processo de desnitrificação. Os óxidos de nitrogênio participam de uma série de reações atmosféricas na formação do ozônio e na produção de ácido nítrico, que contribui para o aumento da acidez da chuva.

$$
3 \mathrm{NO}_{2}(\mathrm{~g})+\mathrm{H}_{2} \mathrm{O}(\mathrm{l}) \rightarrow 2 \mathrm{HNO}_{3}(\mathrm{aq})+\mathrm{NO}(\mathrm{g})
$$

A amônia é um composto reduzido de nitrogênio e um gás no estado padrão. No ciclo do nitrogênio, é gerada no processo de fixação por redução biológica, realizada por cianobactérias. Industrialmente é produzida pelo processo Haber-Bosch, que combina $\mathrm{H}_{2}$ e $\mathrm{N}_{2}$ com auxílio de um catalisador, elevadas pressões e temperaturas brandas $\left(350-400{ }^{\circ} \mathrm{C}\right)$. A amônia é um gás muito solúvel em água $(76,41$ $\mathrm{L} / 100 \mathrm{~mL}$ de água a $20{ }^{\circ} \mathrm{C}$ ), ${ }^{13} \mathrm{com}$ solubilidade que corresponde a mais de 700 volumes de $\mathrm{NH}_{3}$ para um volume de água. ${ }^{9}$ A amônia interage fortemente com a água, via ligações hidrogênio, formando os íons amônio e hidróxido que encontram-se em equilíbrio (equação 13), produzindo misturas azeotrópicas com concentrações máximas de 28-32\%. A solução é comercializada como hidróxido de amônio, tido como uma base fraca.

$\mathrm{NH}_{3}(\mathrm{aq})+\mathrm{H}_{2} \mathrm{O}(\mathrm{l}) \rightleftarrows \mathrm{NH}_{4}^{+}(\mathrm{aq})+\mathrm{OH}^{-}(\mathrm{aq}) \quad K_{\mathrm{b}}=1,8 \times 10^{-5}$

\section{Solubilidade dos gases em meio aquoso e os processos biológicos}

Alguns processos biológicos, fundamentais para a constituição e manutenção da vida, são governados pela participação de gases presentes na atmosfera e, em consequência, de sua solubilidade em fluidos biológicos. Dentre esses processos, cabe destacar dois deles, vistos a seguir.

\section{Respiração}

Oxigênio e dióxido de carbono são gases importantes da atmosfera terrestre, responsáveis por $20,95 \%$ e $0,04 \%$ em volume, respectivamente, na composição do ar seco ao nível do mar. Embora os gases oxigênio e dióxido de carbono sejam constituídos por moléculas apolares, suas densidades eletrônicas são mais suscetíveis à polarização, especialmente o $\mathrm{CO}_{2}$, sendo, portanto, mais solúveis em água do que o nitrogênio, que é o componente majoritário da atmosfera terrestre, com $78,09 \%$ de seu volume total. Oxigênio e dióxido de carbono, dissolvidos em fluidos intra e extracelulares, desempenham funções vitais, como a respiração e a fotossíntese. $\mathrm{Na}$ respiração celular ocorre uma troca de gases, em que dióxido de carbono deixa a célula e oxigênio entra na célula. Oxigênio é necessário para converter a energia armazenada de moléculas orgânicas em ATP, enquanto que o metabolismo celular gera dióxido de carbono que deve ser removido da célula. Os organismos unicelulares realizam essa troca diretamente através da membrana celular, assim como animais simples que possuem formas que permitem essa troca através de suas superfícies corporais. Já os animais maiores desenvolveram diferentes sistemas para realizar a troca de gases e facilitar o transporte nas áreas onde ela ocorre. Nesses sistemas, os gases atravessam a membrana celular quando dissolvidos em uma solução aquosa, o que requer superfícies respiratórias úmidas. Diferentes sistemas de troca de gases foram desenvolvidos por animais aquáticos e terrestres. Por exemplo, as guelras são muito eficientes para extrair o oxigênio da água, onde ele é apenas cerca de 1/20 da quantidade que está presente em um mesmo volume de ar. Por isso, esse sistema de troca foi desenvolvido por animais aquáticos (Figura 4). ${ }^{19}$ 


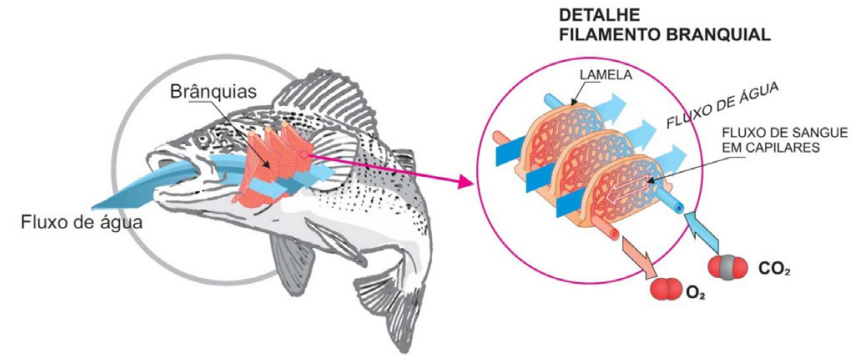

Figura 4. Sistema respiratório desenvolvido por animais aquáticos

Em função de restrições associadas à perda de água, os animais terrestres desenvolveram pulmões mais eficientes. No sistema respiratório humano (Figura 5) o ar entra no corpo pelo nariz, onde é aquecido e filtrado, e vai para a cavidade nasal. Depois passa pela faringe, laringe e traquéia, atingindo os brônquios, que transportam o ar para dentro e fora dos pulmões. As ramificações dos brônquios em tubos cada vez mais finos são chamadas de bronquíolos, com terminações chamadas de alvéolos, que são rodeados por capilares separados por uma fina parede $(0,2 \mathrm{~mm})$.

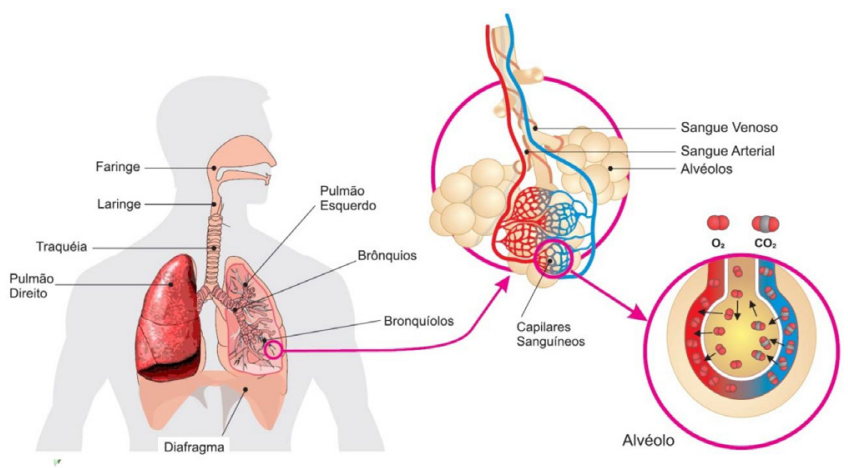

Figura 5. Sistema respiratório humano

O transporte dos gases dos alvéolos, com ar rico em oxigênio, para o interior dos capilares (sangue pobre em oxigênio) através da membrana, dá-se por diferença de pressões parciais. Entretanto, a baixa solubilidade do oxigênio no sangue exige um transportador de $\mathrm{O}_{2}$ eficiente para atender às necessidades do corpo, função desempenhada pela hemoglobina $(\mathrm{Hb})$. Enquanto que $1 \mathrm{~L}$ de plasma sanguíneo é capaz de dissolver $2,3 \mathrm{~mL}$ de $\mathrm{O}_{2}$ a $38{ }^{\circ} \mathrm{C}$, temperatura média do sangue humano, a hemoglobina contida no mesmo volume de sangue é capaz de transportar $220 \mathrm{~mL}$ de $\mathrm{O}_{2} \cdot{ }^{20} \mathrm{O}$ oxigênio contido no sangue, dissolvido no plasma e, principalmente, na forma conjugada com a hemoglobina (oxi-hemoglobina), difunde-se para os tecidos e é transferido para a mioglobina, onde esse será armazenado para atender as demandas das células em diversas funções metabólicas. A perda de oxigênio e o ganho simultâneo de dióxido de carbono convertem o sangue arterial em venoso. O sangue venoso é coletado pelas veias, misturando-se no ventrículo direito e novamente circulado pelos pulmões.

A concentração de dióxido de carbono em células metabolicamente ativas é maior que no sangue, o que permite o seu transporte da célula para o sangue (Figura 6). $\mathrm{O} \mathrm{CO}_{2}$ é cerca de 30 vezes mais solúvel em água que o oxigênio, consequência da maior polarizabilidade da sua nuvem eletrônica e da capacidade de combinar-se com a água para formar íons bicarbonato e íons $\mathrm{H}^{+}$. No entanto, essa reação é muito lenta para atender a necessidade de remoção de $\mathrm{CO}_{2}$ diante de elevada atividade metabólica das células. A reação é, então, catalisada pela enzima anidrase carbônica, que eleva em cerca de $10^{7}$ a ordem de grandeza da constante cinética, ${ }^{21}$ o que permite maior eficiência no processo de remoção de $\mathrm{CO}_{2}$, evitando o acúmulo desse gás no plasma que levaria à ruptura dos capilares pelo aumento excessivo da pressão interna.

O processo de remoção de $\mathrm{CO}_{2}$ é também auxiliado pela hemoglobina. Após transferir o oxigênio para a mioglobina, a desoxi-hemoglobina se combina com uma molécula de água, enquanto a sua parte protéica absorve $\mathrm{H}^{+}$, atuando como agente tamponante (Figura 6).
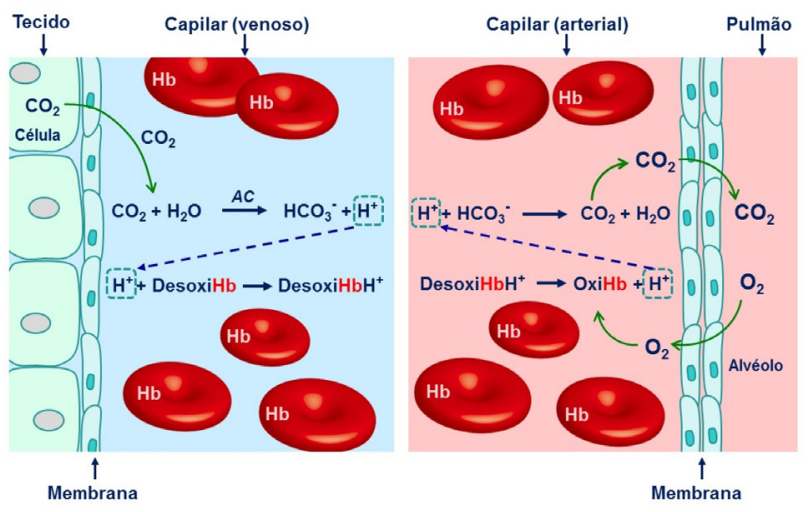

Figura 6. Processo de remoção do dióxido de carbono do sangue. AC: anidrase carbônica

No processo de troca de gases que ocorre através das membranas que separam os capilares dos alvéolos, a desoxi-hemoglobina se associa ao oxigênio e libera $\mathrm{o}^{+}$, este se combina novamente com bicarbonato formando ácido carbônico, que é rapidamente decomposto em dióxido de carbono e água (Figura 6).

Finalmente, $\mathrm{o} \mathrm{CO}_{2}$ difunde-se para os alvéolos, onde sua pressão parcial é menor, fazendo o caminho de volta até a exalação do ar (Figura 6). Esse processo remove o dióxido de carbono do sangue, permitindo um fluxo contínuo da célula para os capilares. Desta forma, as concentrações médias de $\mathrm{CO}_{2}$ e íons bicarbonato no plasma são mantidas em $1,2 \mathrm{mmol} \mathrm{L}^{-1}$ e $24 \mathrm{mmol} \mathrm{L}{ }^{-1}$, respectivamente. ${ }^{20} \mathrm{Os}$ equilíbrios envolvendo essas espécies (equações 14 e 15) resultam em um sistema tampão que regula o pH do sangue, mantendo-o em 7,4. O tampão bicarbonato freará variações bruscas de $\mathrm{pH}$, impedindo alterações significativas do $\mathrm{pH}$ do sangue.

$$
\begin{gathered}
\text { desoxi }-\mathrm{HbH}^{+}+\mathrm{O}_{2}(\mathrm{~g}) \rightleftarrows \text { oxi }-\mathrm{Hb}+\mathrm{H}^{+}(\mathrm{aq}) \\
\mathrm{HCO}_{3}(\mathrm{aq})+\mathrm{H}^{+}(\mathrm{aq}) \rightleftarrows \mathrm{CO}_{2}(\mathrm{~g})+\mathrm{H}_{2} \mathrm{O}(\mathrm{l})
\end{gathered}
$$

Desta forma, para que os indivíduos sejam saudáveis é preciso respirar ar limpo. Entretanto, a Organização Mundial da Saúde $(\mathrm{OMS})^{22}$ alertou, recentemente, no relatório global sobre zonas de perigo para poluição do ar que $92 \%$ da população global respira ar inadequado. Cerca de 3 milhões de mortes prematuras estão associadas à poluição externa do ar e a maioria das emissões que poluem $\mathrm{o}$ ar, especialmente, $\mathrm{NO}_{\mathrm{x}}$ e $\mathrm{SO}_{2}$, são de origem do setor energético, principalmente, da queima de combustíveis. ${ }^{23}$ As causas das mortes estão relacionadas a doenças que afetam os sistemas circulatório e respiratório, como doenças cardiovasculares, derrame, doença obstrutiva pulmonar crônica e câncer de pulmão.

A World Energy Outlook ${ }^{23}$ faz uma projeção alarmante de que o número de mortes prematuras em decorrência da poluição externa do ar deve aumentar para 4,5 milhões em 2040 e quase 90\% dessas mortes serão registradas em países de baixa e média renda, principalmente no sudeste da Ásia e regiões ocidentais do Pacífico. O Brasil aparece nesse cenário com um aumento significativo de mortes comparado aos números de 2015. A estimativa é que passe das 22 mil mortes registradas em 2015 para 36 mil em 2040. 


\section{Fotossíntese}

A fotossíntese envolve um sistema de troca de gases no sentido oposto ao da respiração e pode ser dividida em dois estágios sequenciais: as reações dependentes da luz e as reações independentes da luz, ou o ciclo de Calvin (Figura 7). ${ }^{24,25}$ A luz solar é absorvida pelos fotossistemas I e II (PS I e PS II), conhecidos como esquema Z, o que resulta na excitação de elétrons. Oxigênio é produzido pela oxidação da água no PS II e ATP e NADPH são produzidos no PS I, armazenando a energia solar nas ligações químicas. O oxigênio, pouco solúvel em meio aquoso, deixa o cloroplasto, local onde ocorre a fotossíntese, enquanto que ATP e NADPH fluem através das membranas para o estroma, cujo meio é aquoso, para fornecer a energia necessária na construção de moléculas de carboidratos a partir da redução do $\mathrm{CO}_{2}$ atmosférico (ciclo de Calvin). A disponibilidade de $\mathrm{CO}_{2}$ no estroma irá depender da solubilidade do gás no fluido e será tanto maior quanto maior for a pressão parcial deste gás no ar atmosférico.

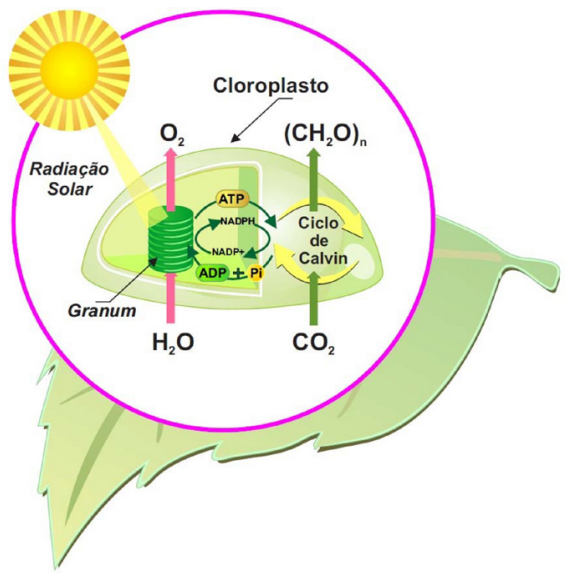

Figura 7. Estágios da fotossíntese: reações dependentes da luz e reações independentes da luz (ciclo de Calvin)

De uma forma geral, a reação global que sumariza a fotossíntese pode ser representada pela equação 16 .

$$
\mathrm{nCO}_{2}+\mathrm{nH}_{2} \mathrm{O}+\text { energia solar } \rightarrow\left(\mathrm{CH}_{2} \mathrm{O}\right)_{\mathrm{n}}+\mathrm{nO}_{2}
$$

\section{Os gases em ambientes aquáticos}

O ambiente aquático é fortemente dependente da solubilidade de oxigênio na água, sendo esse gás proveniente da dissolução do ar atmosférico e da fotossíntese de algas. Além da pressão parcial atmosférica, a solubilidade de oxigênio em corpos d'água será influenciada por fatores como salinidade e, principalmente, temperatura. Ao nível do mar, a solubilidade de $\mathrm{O}_{2}$ em água é de $6,0 \mathrm{~mL} \mathrm{~L}^{-1}$ a $25^{\circ} \mathrm{C} .{ }^{26} \mathrm{Em}$ regiões temperadas, onde a temperatura é menor, a quantidade de oxigênio dissolvido é maior $\left(10,1 \mathrm{~mL} \mathrm{~L}^{-1}\right.$ a $0{ }^{\circ} \mathrm{C}$ e pressão atmosférica de $1 \mathrm{~atm}$ ). Num clima muito frio, no entanto, o gelo, por ser menos denso, cobre a superfície da água, limitando a quantidade de oxigênio disponível. Nessas regiões, o fenômeno de recirculação das águas que ocorre no outono é fundamental para manter o ambiente aquático aerado. Em temperaturas próximas a $4{ }^{\circ} \mathrm{C}$ a água atinge sua densidade máxima. Nessas condições, as águas superficiais se tornam mais densas que as águas mais profundas e assim se deslocam para o fundo, misturando as espécies dissolvidas, como oxigênio, num movimento vertical. Já em regiões tropicais, a quantidade de oxigênio dissolvido diminui por conta da elevação da temperatura $\left(5,3 \mathrm{~mL} \mathrm{~L} \mathrm{~L}^{-1}\right.$ a $30{ }^{\circ} \mathrm{C}$ e pressão atmosférica de $\left.1 \mathrm{~atm}\right)$; porém, isso não significa inviabilidade da vida nesses ambientes, uma vez que os organismos aquáticos tropicais se adaptaram a essa condição ao longo da evolução. No entanto, o aquecimento de corpos d'água em decorrência de atividade humana ocorre em uma janela de tempo muito pequena, o que pode dificultar a adaptação dos seres vivos a essa nova condição, a exemplo do fenômeno de branqueamento de recifes de corais, consequência da perda dos simbiontes com o aumento da temperatura da água. Esses organismos são responsáveis pela cor dos corais e importante fonte de alimento, uma vez que realizam fotossíntese. ${ }^{27}$

A acidificação dos oceanos, também causada pela atividade humana, é uma das consequências do aumento da concentração de $\mathrm{CO}_{2}$ atmosférico. Desde a era pré-industrial, estima-se que a concentração de $\mathrm{CO}_{2}$ na atmosfera aumentou cerca de $40 \%,{ }^{28}$ passando de aproximadamente $280 \mathrm{ppmv}$ (partes por milhão em volume) para 403 ppmv (novembro, 2016) de acordo com os dados da Divisão de Monitoramento Global ligado ao Departamento de Comércio dos Estados Unidos. ${ }^{29}$ A superfície dos oceanos absorve cerca de um terço do excesso de dióxido de carbono injetado na atmosfera pela ação humana, seja por queima de combustíveis fósseis ou por queimada de florestas, tendo como consequências a redução do pH e a diminuição da saturação de carbonato de cálcio nas águas superficiais. Desde os tempos pré-industriais, o $\mathrm{pH}$ médio das águas superficiais caiu cerca de 0,1 unidade, de aproximadamente 8,21 para 8,10 , e a expectativa é que diminua mais $0,3-0,4$ unidades de $\mathrm{pH}$ se as concentrações de $\mathrm{CO}_{2}$ atmosférico continuarem aumentando e atinjam os 800 ppmv, de acordo com projeções do IPCC (Intergovernmental Panel on Climate Change). As reações na água do mar envolvendo o carbono inorgânico dissolvido são reversíveis e próximas ao equilíbrio (equações 2-4). Em pH 8,1, aproximadamente 90\% do carbono inorgânico está na forma de bicarbonato, $9 \%$ na forma de carbonato e apenas $1 \%$ como $\mathrm{CO}_{2}$ dissolvido.

A velocidade de formação e dissolução do carbonato de cálcio (equação 17 ) varia com o estado de saturação $(\Omega)$, definido como o produto iônico das concentrações dos íons cálcio e carbonato (equação 18).

$$
\begin{gathered}
\mathrm{CaCO}_{3}(\mathrm{~s}) \rightleftarrows \mathrm{CO}_{3}{ }^{2-}(\mathrm{aq})+\mathrm{Ca}^{2+}(\mathrm{aq}) \\
\Omega=\left[\mathrm{Ca}^{2+}\right]\left[\mathrm{CO}_{3}{ }^{2-}\right] / \mathrm{Kps}^{\prime}
\end{gathered}
$$

em que Kps'é o produto iônico aparente, que depende da temperatura, salinidade, pressão e a fase cristalina do mineral (aragonita ou calcita).

A concentração de íons cálcio é proporcional à salinidade, enquanto que a concentração de íons carbonato pode ser calculada a partir de dados de carbono inorgânico dissolvido e alcalinidade. A formação de carapaça ou esqueleto em diversas espécies que habitam ambientes marinhos, geralmente ocorre quando $\Omega>1$, enquanto a dissolução do carbonato de cálcio ocorre quando $\Omega<1 .{ }^{28}$ Os estados de saturação são mais elevados em águas tropicais rasas e quentes e mais baixos em regiões de alta latitude, em águas frias e profundas, o que reflete o aumento da solubilidade do $\mathrm{CaCO}_{3}$ com a diminuição da temperatura e aumento da pressão. Desta forma, a capacidade do oceano em absorver $\mathrm{CO}_{2}$ atmosférico causa impacto direto no ambiente marinho.

\section{Os gases na indústria de alimentos: gaseificação de bebidas}

O processo artificial de gaseificação, que realça o paladar e confere frescor à bebida, é chamado de carbonatação. Sua ação refrescante está associada à solubilidade de $\mathrm{CO}_{2}$ na água, que diminui com o aumento da temperatura. Como as bebidas gaseificadas são tomadas geladas, há um aumento da temperatura no trajeto que vai da boca ao estômago. Esse aumento de temperatura associado ao meio ácido estomacal favorece a eliminação do $\mathrm{CO}_{2}$ e a sensação de frescor resulta da expansão desse gás, que é um processo endotérmico. ${ }^{4,30}$ 
O processo de carbonatação é, geralmente, dividido em duas etapas. A primeira consiste na mistura do gás à água, com resfriamento a temperaturas que variam de 4 a $8^{\circ} \mathrm{C}$ para aumentar sua solubilidade. A depender da bebida, outros ingredientes são misturados, como o xarope em refrigerantes. No final do processo, no envasamento, mais $\mathrm{CO}_{2}$ é adicionado com a finalidade de aumentar a pressão parcial do gás e com isso sua solubilidade no meio aquoso. A depender do material da garrafa, a pressão de $\mathrm{CO}_{2}$ pode ser maior ou menor; por exemplo, as garrafas PET têm maior porosidade que as de vidro, o que vai requerer um maior conteúdo de $\mathrm{CO}_{2}$ para compensar perdas por permeação do gás através dos poros. Já as águas gaseificadas naturalmente são consequência do aquecimento subterrâneo em aquíferos próximos a regiões onde ocorrem vulcões ou onde a camada de magma está próxima da superfície. O intenso calor decompõe depósitos calcários contidos na água, liberando dióxido de carbono. Um exemplo é a famosa água mineral natural Perrier, proveniente da localidade de Vergéze na França, que é reforçada com $\mathrm{CO}_{2}$ na fonte por uma corrente de gás de origem vulcânica, que resulta em efervescência e características singulares.

Por outro lado, as cervejas e os espumantes são bebidas gaseificadas naturalmente pelo processo de fermentação. A cerveja para consumo é composta por 2 a $6 \%$ de etanol, 0,35 a 0,50\% de dióxido de carbono, 90 a $95 \%$ de água e 2 a $6 \%$ de extrato residual. O processo de fabricação da cerveja envolve quatro etapas: brassagem; fermentação e maturação; filtração; e envasamento. Na fermentação, as leveduras consomem os carboidratos fermentáveis, produzindo etanol e $\mathrm{CO}_{2}$, como produtos principais, e ésteres, ácidos e álcoois superiores como produtos secundários. Após a fermentação, a cerveja é enviada para tanques maturadores e mantida por períodos variáveis a temperaturas abaixo de $0{ }^{\circ} \mathrm{C}$, o que contribui para a preservação do $\mathrm{CO}_{2}$. No acabamento e envasamento, recebe estabilizantes que mantêm a espuma e antioxidantes para prevenir a influência negativa do $\mathrm{O}_{2}$. Para reter o aroma, recomenda-se tomar a cerveja com colarinho de dois a três dedos de espuma. ${ }^{31}$

O vinho é um produto natural resultante de diversas reações bioquímicas que se iniciam durante a maturação e colheita da uva, são estimuladas durante a fermentação e continuam após o engarrafamento. ${ }^{32}$ Os principais produtos voláteis resultantes das interações microbianas são o etanol e $\mathrm{CO}_{2}$, que não contribuem significativamente para o aroma, ao contrário de ácidos orgânicos, alcoóis superiores, compostos carbonílicos, sulfurados e nitrogenados, lactonas e fenóis voláteis, que constituem o maior grupo de compostos formadores do "bouquet fermentativo". ${ }^{33} \mathrm{Na}$ elaboração de vinhos espumantes, o vinho base, com elevada acidez e menor teor alcoólico, passa pelo processo de segunda fermentação, realizada em ambiente fechado, preservando o $\mathrm{CO}_{2}$ produzido naturalmente. Esse processo resulta na formação lenta de $\mathrm{CO}_{2}$ dentro da garrafa que, quando aberta, produz minúsculas bolhas de gás que transportam aromas e frescor ao nariz e à boca, características essenciais de bons espumantes.

Outro aspecto importante na produção de vinhos é a adição de compostos à base de oxoânions de enxofre $\left(\mathrm{Na}_{2} \mathrm{~S}_{2} \mathrm{O}_{5}\right.$ ou $\mathrm{K}_{2} \mathrm{~S}_{2} \mathrm{O}_{5}$ - metabissulfito de sódio ou potássio e/ou $\mathrm{NaHSO}_{3}$ ou $\mathrm{KHSO}_{3}$ - bissulfito de sódio ou potássio) para solucionar os problemas de oxidação e interferências microbianas indesejadas durante a fermentação. $\mathrm{O}$ $\mathrm{SO}_{2}$ liberado na dissolução desses compostos controla as reações de oxidação e atua também inibindo o crescimento de leveduras nativas e bactérias através da redução da atividade específica da ATPase. ${ }^{34,35}$ A espécie de enxofre predominante no meio aquoso é fortemente dependente do $\mathrm{pH}$ (equação 19). Em um processo típico de elaboração de vinhos a faixa de $\mathrm{pH}$ é de 3-4, sendo o bissulfito a espécie predominate. ${ }^{36}$

$\mathrm{SO}_{2}(\mathrm{~g})+\mathrm{H}_{2} \mathrm{O}(\mathrm{l}) \stackrel{\mathrm{pH}=1,8}{\rightleftharpoons} \mathrm{H}^{+}(\mathrm{aq})+\mathrm{HSO}_{3}^{-}(\mathrm{aq}) \stackrel{\mathrm{pH}=6,9}{\rightleftharpoons} 2 \mathrm{H}^{+}(\mathrm{aq})+\mathrm{SO}_{3}^{2 \cdot}(\mathrm{aq})$
Os compostos carbonílicos presentes no vinho reagem com o bissulfito, levando à formação de ácidos alquilsulfônicos,${ }^{36}$ num mecanismo semelhante ao que ocorre em reações na atmosfera envolvendo $\mathrm{SO}_{2}$ e formaldeído, que resulta na formação de um aduto formaldeído-bissulfito (ácido hidroximetanosulfônico). ${ }^{37} \mathrm{O}$ acetaldeído também reage rapidamente com o bissulfito, formando o ácido $\alpha$-hidroxietanossulfônico, não volátil, que diminui a percepção olfativa indesejável do acetaldeído presente no vinho. ${ }^{36}$

\section{Solubilidade de gases em sólidos}

A solubilidade dos gases em sólidos está diretamente relacionada a um tema que desperta grande interesse atualmente, desde que poderá alterar significativamente a matriz de combustíveis utilizados na frota veicular. Um dos grandes desafios atualmente para a consolidação da economia de hidrogênio é o desenvolvimento de tecnologias capazes de armazenar esse combustível de forma segura e acessível. O hidrogênio pode ser armazenado nas formas gasosa, líquida ou sólida: 1) como gás, comprimido em tanques altamente pressurizados; 2) como líquido, em tanques criogênicos e 3) como sólido, em hidretos metálicos ou materiais nanoestruturados. ${ }^{38} \mathrm{O}$ hidrogênio tem baixa densidade volumétrica de armazenamento e mesmo sob elevadas pressões o sistema de armazenamento requererá grandes volumes. Na forma de líquido, há aumento da densidade volumétrica de armazenamento, mas o sistema requer resfriamento a $20 \mathrm{~K}$. Por essas razões, os sistemas de armazenamento de hidrogênio na forma de gás e líquido são pouco atrativos para aplicações em veículos. As tecnologias alternativas de armazenamento de hidrogênio no estado sólido, por adsorção em materiais nanoestruturados ou por formação de hidretos metálicos, têm despertado grande interesse em grupos de pesquisa ao redor do mundo. No primeiro caso, o hidrogênio é adsorvido ao material nanoestruturado pelos processos de quimissorção ou fisissorção e permanece na sua forma física original. Neste caso, é possível adsorver hidrogênio à temperatura ambiente, mas a quantidade adsorvida será proporcional à pressão aplicada. Já o segundo caso, trata-se de um sistema de armazenamento químico em que o hidrogênio é absorvido sob pressões moderadas e baixas temperaturas. Certos metais, especialmente elementos dos blocos $d$ e $f$, compostos intermetálicos ou ligas, têm habilidade de absorver hidrogênio para formar sólidos metal-hidrogênio reversíveis. A capacidade de absorver quantidades variáveis de hidrogênio resulta na formação de compostos não estequiométricos e muitas vezes denominados de soluções sólidas. Desta forma, por absorção a baixas pressões, o hidrogênio pode ser potencialmente armazenado em hidretos metálicos com alta densidade volumétrica, uma alternativa mais segura comparada aos outros métodos.

Para que seja considerado eficiente no armazenamento de hidrogênio por absorção o material deve apresentar baixas temperaturas de absorção/dessorção, elevadas velocidades de hidrogenação/desidrogenação, boa reversibilidade e alta densidade volumétrica de armazenamento de hidrogênio. ${ }^{38-43}$ Os materiais mais estudados para este fim são compostos intermetálicos do tipo $\mathrm{AB}_{5}, \mathrm{AB}_{2}, \mathrm{AB}, \mathrm{A}_{2} \mathrm{~B}$, etc., em que $A$ representa um elemento metálico com elevada afinidade por hidrogênio (geralmente, um elemento do início das séries de transição, $d^{l}$ a $d^{4}$, ou um lantanídio, com tendência a formar hidretos metálicos), enquanto B é um elemento metálico com fraca afinidade por hidrogênio (geralmente, um metal do final das séries de transição, $d^{5}$ a $d^{10}$, localizados na região da Tabela Periódica conhecida como lacuna de hidretos, a exceção de cobre, zinco e paládio). Esta combinação permite que o hidrogênio seja absorvido reversivelmente. A capacidade dos compostos intermetálicos de absorver hidrogênio é dada pela razão H/M (hidrogênio/metal). A estabilidade do hidreto formado é determinada pela pressão de equilíbrio do hidrogênio molecular a 
uma dada temperatura e as propriedades termodinâmicas dos hidretos são, geralmente, descritas por isotermas pressão-composição. ${ }^{39,40}$

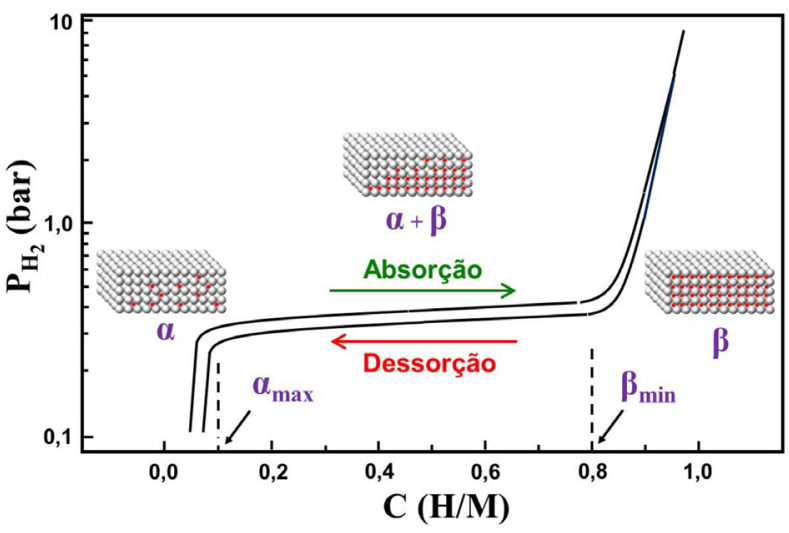

Figura 8. Isoterma pressão-composição de absorção/dessorção de $\mathrm{H}_{2} \mathrm{em}$ compostos intermetálicos (adaptada da ref. 40)

A Figura 8 ilustra uma isoterma pressão-composição típica para absorção/dessorção de $\mathrm{H}_{2}$ em compostos intermetálicos, com destaque para três situações: (1) $\mathrm{H} / \mathrm{M}<0,1$, trata-se de uma solução sólida monofásica de hidreto que apresenta baixo conteúdo de hidrogênio, chamada fase $\alpha$; (2) $0,1<\mathrm{H} / \mathrm{M}<0,8$, há coexistência de duas fases, a fase saturada $\alpha$ que se transforma na fase $\beta$, com maior conteúdo de hidrogênio. Nesta situação, a pressão de equilíbrio do hidrogênio gasoso é mantida constante com o aumento da razão $\mathrm{H} / \mathrm{M}$, tendo-se um plateau de pressão, cujo comprimento determina a quantidade de $\mathrm{H}_{2}$ que pode ser armazenada reversivelmente com pequenas variações de pressão. Deste modo, a formação e decomposição dos hidretos ocorrem no plateau de pressão, que é caracterizado pelo fenômeno de histerese, no qual a pressão de equilíbrio de hidrogênio durante o processo de absorção é ligeiramente maior que a de dessorção para compensar a energia necessária para expansão de rede; e (3) $\mathrm{H} / \mathrm{M}>0,8$, a fase $\alpha$ é totalmente convertida a fase $\beta$, o sistema volta a ser monofásico e a pressão de hidrogênio aumenta abruptamente com o aumento da razão H/M.

Alguns desses materiais são adequados para aplicações não-automotivas como dispositivos móveis, fontes de energia estacionárias e tecnologias aeroespaciais, a exemplo das baterias de $\mathrm{Ni} / \mathrm{MH}$ recarregáveis, constituídas por ligas intermetálicas do tipo $\mathrm{AB}_{5}, \mathrm{AB}_{2} \mathrm{e} \mathrm{AB}$, que atuam como eletrodo negativo nestas baterias. As ligas derivadas de $\mathrm{LaNi}_{5}$ são as mais utilizadas, ${ }^{43}$ porém, a capacidade gravimétrica de armazenamento de hidrogênio em $\mathrm{LaNi}_{5} \mathrm{H}_{6.5}$, por exemplo, é menor que $2 \%(\mathrm{~m} / \mathrm{m})$, inviabilizando o uso em veículos automotivos. Por outro lado, há um grande esforço internacional no sentido de identificar hidretos metálicos adequados a aplicações automotivas e que tenham baixo custo, capaz de viabilizar o uso. O Departamento de Energia dos Estados Unidos (DOE) projetou para o ano de 2017 valores ideais de capacidade de armazenamento de hidrogênio de sistemas para uso em veículos equipados com células a combustível. ${ }^{38,41,44} \mathrm{O}$ objetivo é desenvolver sistemas de armazenamento de hidrogênio com capacidade gravimétrica de $5,5 \%\left(\mathrm{~kg} \mathrm{H}_{2} / \mathrm{kg}\right)$ e uma capacidade volumétrica de $4 \%\left(\mathrm{~kg} \mathrm{H}_{2} / \mathrm{L}\right)$, operando na faixa de temperatura de -40 a $60{ }^{\circ} \mathrm{C}$ e pressão de 5 a 12 bar. ${ }^{44}$ A Tabela 3 apresenta alguns compostos intermetálicos já avaliados e compara suas capacidades gravimétricas de armazenamento com a do paládio, conhecido como "esponja de hidrogênio".

As ligas que alcançaram maiores capacidades gravimétricas de armazenamento ainda requerem altas pressões e elevadas temperaturas. Deste modo, apesar da grande concentração de esforços, até o presente momento, o desenvolvimento de sistemas com capacidade
Tabela 3. Capacidade gravimétrica de armazenamento de compostos intermetálicos ${ }^{38,39}$

\begin{tabular}{lccc}
\hline Tipo & Composto intermetálico & $\%(\mathrm{~kg} \mathrm{H} / \mathrm{kg})$ & $\begin{array}{c}p_{\text {eq }} \text { (bar) } / \\
\text { Temperatura }(\mathrm{K})\end{array}$ \\
\hline & $\mathrm{LaNi}_{5}$ & 1,37 & $2 / 298$ \\
$\mathrm{AB}_{5}$ & $\mathrm{CeNi}_{4} \mathrm{Zr}$ & 4,00 & $32 / 293-333$ \\
& $\mathrm{CeNi}_{4} \mathrm{Cr}$ & 4,30 & $31 / 293-333$ \\
\hline & $\mathrm{ZrV}_{2}$ & 3,01 & $10-8 / 323$ \\
$\mathrm{AB}_{2}$ & $\mathrm{ZrMn}_{2}$ & 1,77 & $1 / 440$ \\
& $\mathrm{Zr}_{0.9} \mathrm{Ti}_{0.1} \mathrm{Cr}_{0.8} \mathrm{~V}_{0.8} \mathrm{Ni}_{0.4}$ & 2,00 & $1 / 373$ \\
\hline \multirow{2}{*}{$\mathrm{FB}$} & $\mathrm{FeTi}$ & 1,89 & $5 / 303$ \\
\hline $\mathrm{A}_{2} \mathrm{~B}$ & $\mathrm{Ti}_{0.5} \mathrm{~V}_{0.5} \mathrm{Mn}$ & 1,90 & $350 / 260$ \\
\hline Elemento & $\mathrm{Mg} \mathrm{Ni}_{2}$ & 3,59 & $1 / 555$ \\
\hline
\end{tabular}

gravimétrica de armazenamento de hidrogênio projetada pelo DOE ainda é considerado um desafio. Além dos hidretos metálicos, compostos como hidroboratos, $\mathrm{MBH}_{4}$ e $\mathrm{M}\left(\mathrm{BH}_{4}\right)_{2}$ (em que $\mathrm{M}$ é $\mathrm{Li}, \mathrm{Na}$, $\mathrm{Mg}$ ou $\mathrm{Ca}$ ) e alanatos, $\mathrm{MAlH}_{4}$ (em que $\mathrm{M}$ é $\mathrm{Na}, \mathrm{Li}$ ou K ), também são alvos de investigação. ${ }^{38,39}$

\section{CONCLUSÕES}

Diversos processos biológicos, industriais e que ocorrem na atmosfera e em corpos d'água dependem da capacidade de dissolução de gases em água e podem ser usados para abordar o fenômeno da solubilidade. A solubilidade de gases em água depende majoritariamente da polarizabilidade de átomos ou moléculas que os constituem e de sua capacidade em reagir com o solvente. Quando a polarizabilidade for alta e a dissolução for acompanhada de reação, as constantes de Henry serão elevadas e outros equilíbrios estarão envolvidos, além do processo de solvatação. Por outro lado, a solubilidade de gases em sólidos é importante no desenvolvimento de tecnologias eficientes de armazenamento de hidrogênio que viabilizará o uso de células a combustível tanto em dispositivos estacionários quanto na frota veicular, contribuindo para a substituição da atual matriz energética. Variáveis importantes que devem ser consideradas na avaliação da solubilidade de gases, seja em meio de dispersão líquido ou sólido, são a temperatura e a pressão. O aumento da pressão contribuirá sempre de forma positiva para a solubilidade de gases em meio de dispersão líquido ou sólida, porém, o aumento da temperatura exercerá efeitos contrários a depender da fase de dispersão. No caso de solvente líquido, o aumento da temperatura reduz a solubilidade dos gases devido à redução da intensidade das forças intermoleculares. Já o efeito do aumento de temperatura é positivo para a solubilidade de gases em fase de dispersão sólida pelo processo de absorção, visto que envolve quebra e formação de ligações químicas.

Finalmente, cabe destacar que este artigo vem fechar um ciclo de discussão que aborda o tema solubilidade, e que teve seu início em 2004. O primeiro registrava em seu título uma provocação à discussão: "Por que todos os nitratos são solúveis?"; ${ }^{45}$ essa provocação foi mantida no segundo, que trazia a indagação "Sulfetos: Por que nem todos são insolúveis?". ${ }^{46}$ A solubilidade dos compostos orgânicos também foi tratada, no artigo: "Solubilidade de substâncias orgânicas", ${ }^{47}$ o qual este sucede. Assim, com esta série de discussão espera-se abranger as fases condensadas e gasosa da matéria, bem como envolver espécies químicas de naturezas distintas, contribuindo para uma melhor compreensão desse importante fenômeno. 


\section{AGRADECIMENTOS}

Ao CNPq e FAPESB pelas bolsas e financiamentos e aos três revisores de Química Nova pelos excelentes comentários e sugestões que contribuíram substancialmente para a melhoria do manuscrito.

\section{REFERÊNCIAS}

1. Mészáros, E.; Atmospheric Chemistry: Fundamental Aspects, 1981, Elsevier Scientific Publishing Company: Amsterdam, 1981.

2. Jardim, W. F.; QNEsc, Cadernos temáticos 2001, 5, 5.

3. Martins, C. R.; Pereira, P. A. P.; Lopes, W. A.; de Andrade, J. B.; QNESC, Cadernos temáticos 2003, 5, 28.

4. Atkins, P.; de Paula, J. B.; Atkins Físico-Química, Vol. 1, 7ª Ed., Livros Técnicos e Científicos Ed. S.A.: Rio de Janeiro, 2004.

5. http://qnint.sbq.org.br/novo/. Acessada em fevereiro de 2017.

6. Werner, H-J.; Rosmus, P. J. Chem. Phys. 1980, 73, 2319.

7. Lide Jr., D. R. J. Phys. Chem. 1960, 33, 1514.

8. Haynes, W. M. In Handbook of Chemistry and Physics; Haynes, W. M., Lide, D. R., Bruno, T. J., eds.; $95^{\text {th }}$ ed., CRC Press, Inc: New York, 2014-2015.

9. Atkins, P.; Jones L.; Chemistry: Molecules, Matter, and Changes, Ed. Freeman: New York, 1997.

10. Lee, J. D.; Química Inorgânica não tão concisa, Tradução da $5^{\mathrm{a}}$ ed. inglesa, Ed. Edgard Blücher: São Paulo, 1999.

11. Rocha, W. R.; QNEsc, Cadernos temáticos 2001, 4, 31.

12. Greenwood, N. N.; Earnshaw, A.; Chemistry of the Elements; $2^{\text {nd }}$ ed., Butterworth Heinemann: Oxford, 1997.

13. http://gestis-en.itrust.de. Acessada em fevereiro de 2017.

14. Grover, A. C.; Grover, D. H.; J. Emerg. Med. 2014, 46, 225.

15. Hobbs, M.; Kneller, W.; Physiol. Behav. 2015, 144, 46.

16. Rezende, W.; Lopes, F. S.; Rodrigues, A. S.; Gutz, I. G. R.; QNEsc 2008, 30,66 .

17. Brasseur, G. P.; Orlando, J. J.; Tyndall, G. S.; Atmospheric Chemistry and Global Change, Oxford: New York, 1999.

18. Hawkes, S. J.; J. Chem. Educ. 1993, 70, 836.

19. Purves, W. K.; Orians, G. H.; Heller, H. C. R.; Life: The Science of Biology, $4^{\text {th }}$ ed., Sinauer Associates Inc: Sunderland, 1994.

20. Chemello, E.; Naeq - Núcleo de Apoio ao Ensino de Química, Textos Interativos - "O equilíbrio ácido-base no sangue"; http://www.quimica. net/emiliano/equilibrio_acido_base_sangue.html. Acessada em fevereiro de 2017.

21. Kaim, W.; Schwederski, B.; Bioinorganic Chemistry: Inorganic Elements in the Chemistry of Life. An Introduction and Guide, John Wiley \& Sons: Hoboken, 1996.
22. http://www.who.int/mediacentre/news/releases/2016/air-pollution-rising/ en/. Acessada em fevereiro de 2017.

23. Energy and Air Pollution 2016 - World Energy Outlook Special Report. http://www.worldenergyoutlook.org/. Acessada em fevereiro de 2017.

24. Kluge, R. A.; Tezotto-Uliana, J. V.; da Silva, P. P. M.; Rev. Virtual Quim. 2015, 7, 56.

25. Fridlyand, L. E.; Scheibe, R.; BioSystems 1999, 51, 79.

26. Fiorucci, A. R.; Benedetti-Filho, E.; QNESc 2005, 22, 10.

27. Kavousi, J.; Reimer, J. D.; Tanaka, Y. Nakamura, T.; Mar. Environ. Res. 2015, 109, 9.

28. Doney, S. C.; Fabry, V. J.; Feely, R. A.; Kleypas, J. A.; Annu. Rev. Mar. Sci. 2009, 1, 169.

29. http://www.esrl.noaa.gov/gmd/ccgg/trends/. Acessada em fevereiro de 2017.

30. Lima, A. C. S.; Afonso, J. C.; QNESc 2009, 31, 210.

31. Rosa, N. A.; Afonso, J. C.; QNESc 2015, 37, 2, 98.

32. Romano, P.; Fiore, C.; Paraggio, M.; Caruso, M.; Capece, A.; Int. J. Food Microbiol. 2003, 86, 169.

33. Flanzy, C.; Enologia: Fundamentos Científicos y Tecnológicos, $1^{\text {a }}$ ed., Mundi Prensa \& A. Madrid Vicente Ediciones: Madrid, 2000.

34. Carreté, R.; Vidal, M. T.; Bordons, A.; Constanti, M.; FEMS Microbiol. Lett. 2002, 211, 155.

35. Azevêdo, L. C.; Reis, M. M.; Silva, L. A.; de Andrade, J. B.; Quim. Nova 2007, 30, 1968

36. Azevêdo, L. C.; Reis, M. M.; Motta, L. F.; da Rocha, G. O.; Silva, L. A.; de Andrade, J. B.; J. Agric. Food Chem. 2007, 55, 8670.

37. de Andrade, M. V. A. S.; Pinheiro, H. L. C.; Pereira, P. A. P.; de Andrade, J. B.; Quim. Nova 2002, 25, 1117.

38. Rusman, N. A. A.; Dahari, M.; Int. J. Hydrogen Energy 2016, 41, 12108.

39. Schlapbach, L.; Züttel, A.; Nature 2001, 414, 353.

40. Cuevas. F.; Joubert, J.-M., Latroche, M.; Percheron-Guégan, A.; Appl. Phys. A: Mater. Sci. Process. 2001, 72, 225.

41. Ahluwalia, R. K.; Peng, J.-K.; Hua, T. Q. Int. J. Hydrogen Energy 2014, 39, 1487.

42. Tan, Semra; Shen, Yang; Sahin, E. O.; Noréus, D.; Ozturkb, T. Int. J. Hydrogen Energy 2016, 41, 9948.

43. Falahati, H.; Barz, D. P. J. Int. J. Hydrogen Energy 2013, 38, 8838.

44. http://energy.gov/sites/prod/files/2014/03/f12/targets_onboard_hydro_ storage.pdf. Acessada em fevereiro de 2017.

45. Silva, L. A.; Martins, C. R.; de Andrade, J. B.; Quim. Nova 2004, 27, 1016.

46. Martins, C. R.; Silva, L. A.; de Andrade, J. B.; Quim. Nova 2010, 33, 2283.

47. Martins, C. R.; Lopes, W. A.; de Andrade, J. B.; Quim. Nova 2013, 36, 1248. 